\title{
Introducing the Sustainability Challenge of Textiles and Clothing
}

\author{
Magnus Boström ${ }^{1} \cdot$ Michele Micheletti $^{2}$
}

Received: 29 September 2016 / Accepted: 29 September 2016 /

Published online: 28 October 2016

(C) Springer Science+Business Media New York 2016

As emphasized in the collection of articles for this special issue, clothing and textile production is one of the most polluting industries in the world. Its sustainability challenge involves multiple, interrelated, and complicated issues. Textiles and clothing now play a key role in the global public discourse on climate change, chemical society, water shortage, and human rights. Their production and consumption raise several questions and worries that create challenges about how people live their political, social, and economic lives. Many of the challenges concern several common societal and private practices and the role of various and often conflicting values associated with production and consumption. A large number of different actors and institutions from the corporate, governmental, civil society, media, and private spheres are involved as well. While there are technological solutions that solve some of the challenges, others require committed actions on the part of consumers, NGOs, government, business, and others; and increasingly so on an international scale. Particularly businesses and consumers have been identified as key actors here, due to the nature of the fast textile and fashion industry. Policy makers and activists ponder how businesses and consumers can be encouraged to take responsibility, take voluntary steps towards sustainability improvements, and at times even be outright forced to change their choices and behaviours. The deeper question is, however, whether, how, and to what degree they can take on new responsibility for ensuring that textile and clothing production becomes more sustainable. What mechanisms are currently used and which ones can be devised to make this happen? And how well are the ones presently in place working to solve this industry's sustainability challenge?

Scholars stress that the problem areas in globalized textile and clothing production are highly complex. Technological fixes aside, they find that modifying behaviour and practice often requires the more complicated task of working with changing the values associated with production and consumption and doing so in a way sensitive to different cultural, geographic, and political contexts.

Magnus Boström

magnus.bostrom@oru.se

Michele Micheletti

michele.micheletti@statsvet.su.se

1 Örebro University, Örebro, Sweden

2 Stockholm University, Stockholm, Sweden 
Accumulated research also suggests that better information and communication from governments, activists, businesses, educational institutions, the media, and others are necessary. But as discussed in this special issue, the big question is how "better" should be defined, how more effective communication can be formulated and framed, and, finally, which actors are the best able to communicate it broadly. Thus, finding appropriate solutions for the numerous environmental, workers' treatment, and economic issues within the globalized fashion-driven textile and clothing market industry require innovative thinking and efforts on both the supply and demand side at multiple societal and governmental levels. The particular sustainability challenge is this need for a functioning interplay between supply side and demand side actors that brings in sustainable values and practices more directly into focus. This special issue analyses the sustainability challenge by focusing on the role of responsibility among the various actors and institutions involved in the production and consumption of textiles and clothing. It asks how the sustainability impact and also measures towards progress are and should be distributed among them. Its articles focus on how responsibility for sustainability is presently working, and they use innovative research designs to identify important factors and mechanisms that promote and hinder more sustainable consumer and business practice.

\section{Sustainability Impact and Responsibility: the Role of Supply and Demand Side Actors}

The responsibility challenge of the textile and clothing sector is closely related to the rapid globalization of trade in the recent decades (Gereffi 1999). In the face of global competition and an aggressive race for increasing market shares, big brand retailers in the textile and fashion industry have sought and still seek to reduce manufacturing costs by outsourcing production to developing countries (Gereffi 1999; Kütting 2008; Laudal 2010). They have been successful in operating at low-cost abroad because governments in developing countries have tended and even been encouraged by international institutions to put economic growth before stronger environmental and social regulation. At the same time, governments in the northern hemisphere have not really sought or been able to find effective ways of regulating them. For the textile sector, private regulation, for example in the form of codes of conduct (Locke 2013) or eco-certification (Boström and Karlsson 2013; Boström et al. 2015; De Brito et al. 2008), has recently been emerging but is still quite marginal and ineffective to address problems at their structural roots. Moreover, calls on consumers to improve their consumption choices have not been sufficiently realized and lag behind other sectors. Different reasons for why this is the case are identified, discussed, and examined in this special issue. As discussed in the previous research highlighted in our collection of articles as well as elsewhere, this development often implies that women, minority, and migrant workers and even in some cases children must accept temporary employment contracts, low wages, long working days, and unsafe and unhealthy working environments. Aside from these problems concerning human rights, generally, the industry has a considerable environmental sustainability impact and is, for instance, very demanding with respect to use of chemicals (e.g., for growing cotton and dying textiles), pollution of rivers and other ecosystems as well as land and water use (e.g., for cotton). To this is added the climate impact of this globalized mass consumption and fast fashion industry. The heavy reliance on fast fashion is a crucial issue, because this industry is characterized by low quality, short-term use, frequent clothing replacement, and increasing textile waste; all of which have significant sustainability impact (Ninimäki and Hassi 2011). Compared to many other business sectors, the sustainability impact of this manufacturing 
sector is particularly high, and the global stretch of its commodity chains creates extra challenges both on the side of supply and demand. On the supply side, there are considerable governance challenges as a large variety of actors and national contexts are involved. On the demand side, consumers have become increasingly detached from textile and clothing production contexts, which mean that more communication efforts are required to inform and engage the public about the sustainability impacts of their consumption practices. Simply stated, though there is in general rarely an easy and quick fix in sustainability matters, it is even less so in the textile and clothing sector. The heavy sustainability impact of the sector must accordingly imply both a serious and multifaceted discussion and treatment of responsibility.

Scholars, activists, corporations, policy makers, and others ponder how responsibility for the huge sustainability impact in the clothing and textile market can be distributed in a reasonable, effective, democratically justifiable, and generally acceptable way. As discussed in the articles, they argue that conventional ways of allocating responsibility are inadequate because they provide insufficient mechanisms for this sector to adopt more sustainable practices. For instance, scholars such as Iris Marion Young (2004, 2006, 2010), Luigi Pellizzoni (2004), and Frank De Bakker and André Nijhof (2002) in different ways convincingly show why state or governmental mechanisms must be supplemented with other ones that bring in other societal sectors and actors. The important point which they and other scholars address is that not only is the supply and demand chain globalized but so is its responsibility chain. This is due to three important problem-solving challenges. First, no one government or any one global institution has sufficient jurisdictional and/or policy authority to comprehensively regulate the globalized supply and demand chain in clothing and textiles. Politicians cannot, therefore, create laws with encompassing regulation, and corporate leaders cannot implement operative measures that successfully and effectively cover all problem areas. Second, because the supply and demand chain is long, widespread, and globalized, it is not possible to identify all the actors behind the sustainability problems. Even when it is possible to find a wrong doer, the available mechanisms for holding this actor liable (e.g., corporate fines, worker compensation, production shutdowns, and imprisonment) rarely solve the problem and seldom lead to better practice. They are often insufficient, piecemeal and, importantly, rarely proactive (Young 2006, 2010, Stolle and Micheletti 2013). Nongovernmental organizations that mobilize consumers into boycotts and other political consumer activities are painfully aware of this. Pauline Barraud de Lagerie's article "Conflicts of responsibility in the globalized textile supply chain. Lessons for a tragedy" offers clear illustrations about why and how this is the case.

Therefore, other innovative efforts are necessary. Here, scholars have an important role to play in identifying pathways for innovative efforts, barriers in the way, and variation over space and time. This special issue offers important insights here. To begin, as convincingly shown in Austgulen's article "Environmentally sustainable textile and clothing consumption - What characterises the political textile and clothing consumers?" it is noteworthy that the consumption of clothing and textiles appears to have its own particular logic, which makes this sector special and different from others. Other articles analyse innovative efforts in education that might trigger more sustainable clothing shopping generally ("Exploring the challenges and benefits of clothing acquisition abstinence" by Armstrong et al.) and what ethical business can do to promote it (Egels-Zandén and Hansson's "Supply chain transparency as a consumer or corporate tool: The case of Nudie Jeans Co"). The role of governments as a "collective consumer" and the barriers in the way for local officials to use procurement policy to promote sustainable clothing and textiles ("Greening street-level procurement practice in highly decentralised systems: the case of 
Sweden" by Hall et al.) and the effectiveness of NGOs as whistle blowers (de Lagerie) are theorized and analysed in empirical detail. When seen as a collective unit, the special issue clearly suggests that innovation in mechanisms for awareness-creation, teaching and learning, corporate marketing, government procurement strategies, and cooperation among the involved actors is crucial for more sustainable corporate and consumer practice.

\section{Responsibility for Supply Side Sustainability}

From the supply side view, there are two circumstances that accentuate the problem. On the one hand, social movements and journalists collect experiences and document sweatshop and unsustainable production circumstances, thus targeting the most visible actors in the supply chain as the ones with key responsibility. Such politicization and responsibilization are effective in that these efforts threaten the reputation of big brands and create drivers for various kinds of activities to achieve more sustainable supply chain management in the sector. Accordingly, resources are mobilized, collaborations developing, new standards issued, ecosourcing encouraged, and even new eco-niches carved out (De Brite et al. 2008; Goworek 2011; Ninimäki and Hassi 2011; Boström and Karlsson 2013). On the other hand, because of the globally stretched, complex, and fragmented supply chains, there are enormous governance difficulties. Challenges relate to geographical, cultural, political, legal, communicative, and other gaps (Boström et al. 2015), which in turn create great room for continued misperformance, misunderstandings, and so on throughout the entire supply and demand chain. This kind of responsibilization is, therefore, inadequate as a general problem-solving device. How can responsibility be expanded in such situations? This special issue includes two studies particularly connected to the supply side of the challenges and contestations; efforts to make a jeans company the most transparent one in the world and responsibility debates connected to the collapse of a factory in Bangladesh.

While there have been considerable efforts to increase corporate social responsibility in general (writing sustainability reports, using eco-certification, etc.), there has been less progress in the particular area of supply chain transparency. Supply chain transparency might conceivably be a mechanism by which stakeholders can hold companies accountable for sustainability performance and could imply, for example as Egels-Zandén and Hansson show in their article, disclosing the names of first-tier suppliers or more ambitiously disclosing sustainability conditions at the suppliers by publishing factory audit reports. By such mechanisms, consumers and stakeholders would be able to review sustainability efforts. Egels-Zandén and Hansson study the efforts of Nudie Jeans Company, a firm dedicated to sustainability performance, to become the most transparent company in the world. By interviewing representatives from the company and by analysing how consumers behave on the Nudie website, their study indicates that improved transparency makes consumers more willing to buy products, but that consumers do not tend to actually use the disclosed information to check corporate conduct. They thus found that the transparency tool was more a corporate tool than a consumer tool for affecting change. The attempt to be transparent signals to consumers that the company is responsible and that its products are sustainable. Efforts to increase transparency therefore seem more to be a smart legitimacy-seeking campaign or marketing strategy rather than as a mechanism to increase actual consumer power over the supply chain. A certain level of sustainability knowledge is required for making use of such transparency (Mol 2015), which however can be expected more from organized stakeholders than individual end consumers. 
The study by de Lagerie is an example of discursive political consumerism linked to the general anti-sweatshop movement. More specifically, it concerns a contested debate on judgment of ex post responsibility for a factory explosion in Bangladesh - the Spectrum affair-which killed 64 textile workers. Who was to be blamed? How can injured parties be redressed? What responsibility did the Western client firms have? The European-based antisweatshop NGO Clean Clothes Campaign (CCC) sought to globalize this local scandal into an international affair, showing that the case is not an isolated one of inferior local conditions but involving global circumstances that are related to multinational client firms such as fastfashion retailers (Zara, Carrefour, Scapino, etc.). These NGO activities resulted in involved client firms providing some economic compensation to the workers. The article however shows that such shouldering of responsibility is not a self-evident or natural development. Rather, it requires moral entrepreneurs, contestations (naming, blaming, claiming), and ambiguous interpretations through a dynamic interaction between political consumer campaigns and CSR. The author also raises the question if this NGO effort can be interpreted as a successful one of responsibility taking and CSR. Indeed, client firms rejected the judgement of responsibility that civil society actors inflicted upon them. Instead, they referred to the complexity of the supply chain and that the accident was beyond their control, the responsibilities of local actors, and - to the dissatisfaction of CCC - relabeled their response as an act of humanitarian charity and solidarity rather than liability. The study is a nice illustration of the open and contested nature of responsibility and accountability struggles surrounding supply chains in general and particularly in the textile and clothing industry.

\section{Responsibility for Demand Side Sustainability}

Consumers are the main focus in discussions of the demand side in the field of textiles and clothing consumption. Particularly NGOs hope that they can mobilize and convince consumers into pressuring supply side actors to change their manufacturing practices by threatening not to buy their products if they are not sustainably produced (political consumer buycott), rewarding more sustainable businesses by purchasing their goods (political consumer buycott), and also by reconsidering the role of particularly affordable fast fashion in their lives (political consumer lifestyle changes). After all, many consumers have been mobilized into environmentally friendly shopping for household goods, food, coffee, and wood products. In these other areas, political consumer campaigns have been relatively successful despite geographical and cultural distance from production sites and workers. The question is, therefore, why the textile and clothing sector lags behind. In recent research, scholars have begun to observe and discuss the sector-specific external and internal barriers that confront apparel consumers. They identify factors such as limited knowledge, limited availability of alternative products as well as the role of fashion, societal norms, and status connected with personal visibility, appearance, and style (e.g., Hiller 2010; McNeill and More 2015; Harris et al. 2016). Two articles in this special issue offer further insights into why this kind of sustainability mobilization is a particularly tricky task in the field of clothing and textiles and, thus, suggest that too much hope and responsibility is, at least at present, being placed on individual consumers and families.

First, scholars find that the attractiveness of fast fashion as part of personal good appearance, social status, and social identity creates several barriers for more sustainable clothing and textile shopping habits. Previous research shows that NGO activism, eco-fashion design, and 
marketing have a role to play here. However, the important challenge is to conduct more innovative studies that might offer additional information about what other mechanisms might be used to weaken these barriers further. In the article "Educating for sustainable fashion. Using clothing acquisition abstinence to explore sustainable consumption and life beyond growth," Cosette M. Armstrong and colleagues discuss results from their innovative experiment with fashion-oriented students in higher education who volunteered to abstain from purchasing clothing for a 10-week period as a learning experience. The participants' discussions show that clothing shopping can be addictive, play a similar role as comfort eating in one's life, and that there are individual, social, and cultural drivers behind this consumption. Noteworthy, several participants complained about how market culture and its merchandizing imposed demands for seasonal changes and clothing for holidays, which created a distressful and tempting situation for them that made them break the experiment's rules and succumb to making clothing purchases. Thus, it is not easy for an individual alone to take more responsibility for sustainability. Various social and market pressures are also involved. Interestingly, many participants experienced benefits from the experiment, including saving money, using their present wardrobe creatively, and feeling a sense of self-regulation. This intriguing article suggests that consumers need considerable help to change their clothing consuming habits. Eco-design and eco-fashion might nudge them into more sustainable consumption while fulfilling the individual and social needs of consumption. But to change the cultural drivers, conventional clothing retailers must take more responsibility for bringing sustainability values into their marketing strategies. In short, even though consumers can be assigned to a significant share of the responsibility for sustainability, other actors and societal spheres must help them both to understand their responsibility and help them assume it.

Typically, social movements, environmental and human right groups, special NGOs such as those engaged in "anti-sweatshop" efforts, educators, and also public opinion makers have attempted to raise consumer consciousness on the harmful effects of textile and clothing consumption on workers and nature and to mobilize them to put pressure on market actors. Several NGOs are joined together in transnational networks that universalize a frame within which they mobilize support for sustainable clothing production and consumption. Yet, when compared to many other industries also targeting by political consumer activism, their mobilization attempts have not slowed down or changed the market to any great extent. Marthe Hårvik Austgulen's contribution “Environmentally sustainable textile and clothing consumption - What characterizes the political textile and clothing consumers?" finds that about one third of all consumers in France, Germany, Norway, Sweden, and the UK are political consumers of textiles and clothing. This means that they use political, environmental, and ethical values to inform their consumer choices. The level is however much lower level than the national averages in general for political consumer shopping in these countries. Austgulen offers interesting findings about why this is the case. Importantly, her analyses of her comparative surveys specifically on sustainable clothing purchases emphasize that some of the factors (e.g., education and gender) generally found to correlate strongly with what she terms "generic" political consumerism are not significant here. She also, interestingly, shows that there are different profiles and patterns even among sustainable clothing consumers in highly similar countries. Thus, sustainability mobilizers should consider how they frame their message in particular cultural and geographic contexts and not universalize it too much. However, there are important commonalities that she finds correlate significantly with sustainable clothing shopping. They are a sense of individual responsibility for sustainability, the availability of sustainable clothing on the market in a country, and consumer habits about 
reading clothing labels for information about its contents, manufacturing, and caring (so-called information seeking in the literature). However, other more conventional matters like price, design, wear, and fit still play a key role as part of sustainability clothing shopping. Again, we see that the clothing and textile sector has particular attributes that make it different from other globalized commodity chains. Importantly, the results from the two articles confirm that both supply and demand side actors need to take and share responsibility for providing consumers with information and education so that they can reflect more about the role of their clothing and textile consumption in sustainable development globally and then find available products when they think it is time to make their clothing purchases.

\section{Government's Role}

Also, governmental actors have a role to play as promoters of green consumption - through sustainable procurement. They are different than private sector organizations such as IKEA, Nike, and H\&M because they rely on tax money and particular legislation when making their purchases. Moreover, their actions and choices are subject to public scrutiny and public accountability. Earlier studies have indicated special challenges related to governmental/ public actors on various administrative levels that are related to the greening of public procurement (Preuss 2009; Boström and Karlsson 2013). One challenge is that although procurement legislation may enable or encourage inclusion of green and other sustainability criteria in procurement, public actors cannot go against international free trade rules, which force them to consider principles on equal treatment and non-discrimination among domestic and foreign tenders when they make purchasing decisions. Legal, political, economic, and cognitive factors thus shrink the opportunities for developing more sustainable procurement. Indeed, the development of a non-territorial view of responsibility, which is linked to the complexity of a globalized supply and demand chain perspective, conflict with the traditional mandate of public actors. For public actors, as discussed above, responsibility tends to be contained in a territorial notion (political jurisdiction) connected to representative democracy and welfare provision for tax-paying citizens. This territorial notion creates barriers for more sustainable procurement practices.

Green and sustainability public procurers thus face a substantially different situation than individual political consumers. Recognizing these particular circumstances, Hall, Löfgren, and Peters in this special issue focus on what factors and mechanisms facilitate or constrain public procurement officers' purchases of sustainable textiles. The knowledge contribution from their qualitative study lies particularly in highlighting the role of individual actors (so-called "streetlevel" procurement officers) within public settings. They find that there indeed is some scope for "inside activism" on the part of sustainability-oriented and -mobilized procurement officers who have accumulated considerable environmental expertise knowledge. Yet, unlike individual political consumers, they face political and organizational constraints and cannot simply let their private political priorities decide what they procure publicly. Instead, these procurement officers must find a way of working within conventional governing principles and frameworks that inform the behaviour of public servants, which include such values as compliance to regulation and policy, structural capabilities such as resources, knowledge, and organizations, and, finally, commitment to a policy and policy area. In particular, the authors stress the indirect and direct political and regulatory support that these procurers need from various administrative levels in order for them to pursue more sustainable procurement practices and 
choices. Thus, environmental knowledge and personal motivation are necessary but insufficient. Political-, regulatory-, and organizational-conducive conditions for pro-sustainability action and their associated mechanisms need to be in place.

\section{Conclusion}

On both the supply and demand side, acknowledgement of the plurality and heterogeneity of actors, interests, and values connected to clothing is necessary. This acknowledgement is needed because clothing will continue be soaked with all kinds of socio-cultural distinctions and norms in all societies across the globe. The challenge is then how a plurality of pathway towards sustainability and responsibility can co-exist in fruitful interaction with the very basic human desire to look good, elegant, cool, and clean. The collection of articles in this special issue stresses that all involved actors need support for them to take more responsibility for sustainability in the textile and clothing industry. This applies for all kinds of consumersfrom individual to street-level procurement officials - who might be further encouraged into sustainable practice through innovative consumer tools (e.g., corporate transparency guides, experiential learning in higher education, and procurement policy) that raise their understanding of the interests and actors involved in the making of fast, appealing, and affordable fashion and textiles. Important as well is the crucial role of their ability to engage in reflective awareness on the limits of different tools and expertise, including for instance critical assessment of how and why various actors attempt to create legitimacy for their actions by talking "transparency," "sustainability," and "eco-fashion." Identifying categories of consumers who might be supported as forerunners here is an important task for changing the practice of others, which has the potential of narrowing the gap between cognitive awareness of problems and behavioural change based on it. There is therefore a huge span between choice, dialog/capacity building, and problem solving. It is not possible to distribute responsibility equally. Many individual consumers cannot be expected to do much more than trying to be aware and competent buyers who choose available "ethical" products with a reflective mind, while some collective buyers (public or private) can be much more professional and equipped with expertise knowledge so that they can engage in further stakeholder dialogue and capacity building whose purpose is to promote sustainable and responsible management. An important lesson from this special issue is that sustainability management and responsibility taking must be long term and learning oriented. Sustainability and responsibility for sustainability will always be contested. Therefore, continued public debate on responsibility taking and the responsibility of involved actors is crucial. Research has an important role to play here in identifying strengths and weaknesses in present-day practice and offering suggestions about pathways forward.

\section{References}

Boström, M., \& Karlsson, M. (2013). Responsible procurement, complex product chains and the integration of vertical and horizontal governance. Environmental Policy and Governance, 23(6), 381-394.

Boström, M., Jönsson, A. M., Lockie, S., Mol, A. P. L., \& P., O. (2015). Sustainable and responsible supply chain governance: Challenges and opportunities. Journal of Cleaner Production, 107, 1-7.

De Bakker, F., \& Nijhof, A. (2002). Responsible chain management: A capability assessment framework. Business Strategy and the Environment, 11, 63-75. 
De Brito, M. P., Carbone, V., \& Meunier Blanquart, C. (2008). Towards a sustainable fashion retail supply chain in Europe: Organisation and performance. International Journal of Production Economics, 114, 534-553.

Gereffi, G. (1999). International trade and industrial upgrading in the apparel commodity chain. Journal of International Economics, 48, 37-70.

Goworek, H. (2011). Social and environmental sustainability in the clothing industry: A case study of a fair trade retailer. Social Responsibility Journal, 7(1), 74-86.

Harris, F., Helen, R., \& Dibb, S. (2016). Sustainable clothing: Challenges, barriers and interventions for encouraging more sustainable consumer behaviour. International Journal of Consumer Studies, 40(3), 309-318.

Hiller Connell, K. Y. (2010). Internal and external barriers to eco-conscious apparel acquisition. International Journal of Consumer Studies, 34(3), 279-286.

Kütting, G. (2008). A global political economy of textiles: From the global to the local and back again. In J. Park, K. Conca, \& M. Finger (Eds.), The crisis of global environmental governance (pp. 58-76). London: Routledge.

Laudal T. 2010. An attempt to determine the CSR potential of the international clothing business. Journal of Business Ethics. 96(1), 63-77

Locke, R. M. (2013). The promise and limits of private power. New York: Cambridge University Press.

McNeill, L., \& Moore, R. (2015). Sustainable fashion consumption and the fast fashion conundrum: Fashionable consumers and attitudes to sustainability in clothing choice. International Journal of Consumer Studies, 39, $212-222$.

Mol, A. (2015). Transparency and value chain sustainability. Journal of Cleaner Production, 107, 54-161.

Niinimäki, K., \& Hassi, L. (2011). Emerging design strategies in sustainable production and consumption of textiles and clothing. Journal of Cleaner Production, 19, 1876-1883.

Pellizzoni, L. (2004). Responsibility and environmental governance. Environmental Politics, 13, 541-565.

Preuss, L. (2009). Addressing sustainable development through public procurement: The case of local government supply chain management. An International Journal, 14, 213-223.

Stolle, D., \& Micheletti, M. (2013). Political consumerism: global responsibility in action. Cambridge: Cambridge University Press.

Young, I. M. (2004). Responsibility and global labor justice. The Journal of Political Philosophy, 12(4), 365388.

Young, I. M. (2006). Responsibility and global justice: A social connection model. Social Philosophy and Policy, 23(1), 102-130.

Young, I. M. (2010). Responsibility for justice. Oxford: Oxford University Press. 